\title{
Bicyclol induces cell cycle arrest and autophagy in HepG2 human hepatocellular carcinoma cells through the PI3K/AKT and Ras/Raf/MEK/ERK pathways
}

\author{
Yu Wang, Hao Nie, Xin Zhao, Yong Qin ${ }^{*}$ and Xingguo Gong*
}

\begin{abstract}
Background: Bicyclol, a novel synthetic antihepatitis drug, is widely known to protect against liver injury. However, few reports have focused on the possible effect of bicyclol on anti-proliferation and autophagy induction in cancer cells, particularly hepatocellular carcinoma cells.

Methods: In this study, we investigated the antitumor efficacy of Bicyclol in HepG2 cells and the mechanism of cell growth inhibition. Cell proliferation was analyzed by MTT assay, and the cell cycle and apoptosis were assessed by flow cytometry. And we transfected the cells with the GFP-RFP-LC3 vector to detect the autophagy flux in the cells. Mechanisms of bicyclol-induced cell growth inhibition were probed by western blot analysis.

Results: Bicyclol effectively inhibited HepG2 cell proliferation in a dose- and time-dependent manner. In addition, we found that bicyclol inhibited cell cycle progression at G1 phase and induced autophagy in HepG2 cells, which implied that the significant decrease in cell proliferation was mainly induced by autophagy and inhibition of cell proliferation. Furthermore, western blot showed that bicyclol inhibited phosphorylation of Akt and ERK, down-regulated the expressions of cyclin D1, cyclin E2, CDK2, CDK4, p-Rb and p-mTOR. Moreover, AKT or ERK knockdown by siRNA enhanced bicyclol-induced autophagy and inhibition of cell proliferation.

Conclusion: These results suggest that bicyclol has potent anti-proliferative activity against malignant human hepatoma cells via modulation of the PIJK/AKT pathway and the Ras/Raf/MEK/ERK pathway, and indicate that bicyclol is a potential liver cancer drug worthy of further research and development.
\end{abstract}

Keywords: Bicyclol, Cell cycle, Autophagy, AKT, ERK, HepG2

\section{Background}

Liver cancer is the fifth most common cancer worldwide, and the second most frequent cause of cancer death [1]. The highest liver cancer rates and deaths were found to occur in China in 2008 [2]. In the USA, the liver cancer incidence rates continued to increase by at least $3 \%$ per year from 1992 to 2009, which was the highest of all cancers. Despite extensive research into treatments of liver cancer, such as chemotherapy, hepatectomy, liver transplantation, microspheres, and immunotherapy, survival rates are $3-5 \%$ in cancer registries in developed countries,

\footnotetext{
* Correspondence: happy_ququ@126.com; gongxg@zju.edu.cn Institute of Biochemistry, College of Life Sciences, Zijingang campus,

Zhejiang University, Room 345, Hangzhou 310058, Zhejiang, China
}

and consistently low rates are estimated worldwide [3, 4], which highlights the urgent need for novel effective therapeutic approaches.

Bicyclol (4,4'-dimethoxy-5,6,5,6'-Bis(dimethylene-dioxy)2-hydroxymethyl-2'-methoxy carbonyl biphenyl, Fig. 1a [5]) is a new synthetic antihepatitis drug. It has been widely used in the clinic to treat patients with chronic hepatitis $B$ viral infections [6]. In mice and rats, bicyclol effectively protects against liver injury induced by various hepatotoxins, such as acetaminophen [7], $\mathrm{CCl}_{4}$ [8], alcohol [9], concanavalin A [6], lipopolysaccharide and d-galactosamine [5]. Additionally, bicyclol can improve liver function and partially inhibits hepatitis B virus replication in the clinic [10]. 


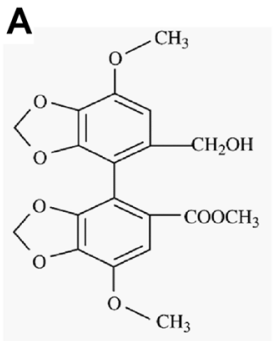

C

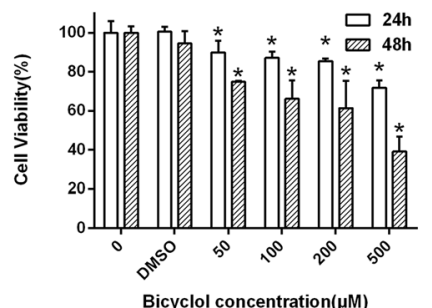

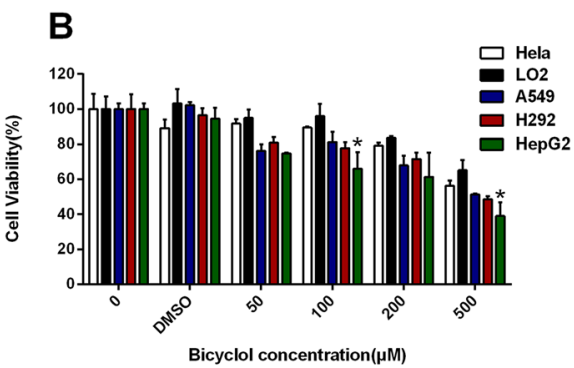

D

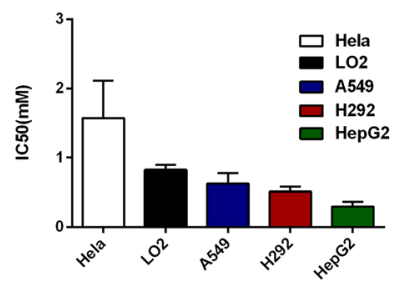

Fig. 1 The effect of bicyclol on the living cell number of cancer cell lines and normal liver cells. a Chemical structure of bicyclol. b The effect of various concentrations of bicyclol on HepG2, Hela and LO2 cells after 48 h of treatment. DMSO-treated (0.25 \%) cells were used as vehicle controls. A570 was measured after the MTT incubation. c dose- and time-dependent effect of bicyclol on the living cell number of HepG2 cells. The bar graphs represent the means \pm SD from three independent experiments. $\mathbf{d}$ The IC50 values at $48 \mathrm{~h}$ in different cells. The bar graphs represent the $95 \%$ confidence intervals

Recently, it was reported that bicyclol effectively induces the cytoprotective effect of heat shock protein $27 / 70$ by suppressing NF-kB in mice [11, 12], and it has similar effects in HepG2 cells through the mitochondria-associated pathway [13]. However, there were few studies about the possible effect of bicyclol on anti-proliferation and autophagy induction in cancer cells, particularly hepatocellular carcinoma cells.

Recent studies have shown that a series of chemical compounds have anti-proliferation effect in cancer cells through the PI3K/AKT pathway. The PI3K/Akt pathway plays an important role in angiogenesis, apoptosis, cell cycle progression, cell survival and cell differentiation. Upon PI3K activation, the Akt PH domain interacts with PtdIns(3,4,5)P3 and recruits Akt to the plasma membrane, where it is then activated through phosphorylation at Thr308 in the activation loop of the catalytic domain and Ser473 in the regulatory domain $[14,15]$. Akt modulates the function of many downstream substrates, such as mTOR, p27 and Mdm2, which are involved in the regulation of the cellular processes mentioned above [16].

In hepatocellular carcinoma cells (HCC), the PI3K/ Akt/mTOR pathway and the Ras/Raf/MEK/ERK pathway have a synergetic relationship in regulating the proliferation of tumor cells [17]. The classic Ras/Raf/MEK/ ERK pathway is a key signal transduction component of cell proliferation in many cells [18]. It contains a cascade of protein kinases: Ras, Raf, MEK, and ERK. One of the key roles of the Ras/Raf/MEK/ERK pathway in many cell types is the regulation of the cell division cycle [19]. It is reported that the p27Kip1 expression is induced by Ras/Raf/MEK/ERK pathway inhibition, and cyclin/cyclin-dependent kinase 2 (CDK2) activity was also inhibited [20].

In the present study, we investigated the effects of bicyclol on HepG2 cells and further examined the cell anti-proliferation mechanism. Our observations demonstrate that bicyclol effectively inhibits HepG2 cell proliferation, but is minimally toxic to normal liver LO2 cells; the significant decrease in cell proliferation was mainly induced by autophagy and inhibition of cell proliferation. Mechanistically, we further identified the cytotoxicity of bicyclol is closely associated with the inhibition of the PI3K/AKT and Ras/Raf/MEK/ERK pathways. These preclinical studies suggest that bicyclol could be useful for the treatment of liver cancer.

\section{Methods \\ Materials}

Bicyclol ( $\geq 98 \%$, HPLC) was purchased from Sigma, dissolved in dimethylsulfoxide (DMSO) and diluted to the desired concentration before use; the final concentration of DMSO was less than $0.3 \%$ in culture. 3-(4,5-Dimethylthiazol-2-yl)-2,5-diphenyltetrazolium bromide (MTT) was purchased from Sigma.

The primary antibodies were purchased from the following companies: Cell Signaling Technology ( $\mathrm{p}-\mathrm{Rb}$, 
Cyclin D1, Cyclin E2, LC3, p-mTOR) and Sangon Biotech (p21, p27, CDK2, CDK4, Akt, p-Akt, p-ERK, Ras). All other chemical reagents were of the highest purity available. The secondary antibody conjugated with Alexa Fluor 680 was purchased from Jackson ImmunoResearch Laboratories, Inc. The cell cycle and apoptosis analysis kit was purchased from Beyotime Biotechnology.

The LO2 (human normal liver), HepG2 (hepatocellular adenocarcinoma), A549 (human lung epithelial cells), H292 (human mucoepidermoid pulmonary carcinoma) and HeLa (cervical carcinoma) cell lines were obtained from the Cell Bank of Type Culture Collection of Chinese Academy of Sciences (Shanghai, China). All cell lines were cultured in RPMI 1640 medium (Gibco), which contained $10 \%$ (v/v) fetal calf serum (Gibco), 100 units/ml penicillin, and 100 units $/ \mathrm{ml}$ streptomycin. The cell lines were cultured in a humidified cell incubator at $37{ }^{\circ} \mathrm{C}$ with a $5 \%$ $\mathrm{CO}_{2}$ atmosphere.

LY294002, 3-MA, benzyloxycarbonyl-Val-Ala-Asp(OMe) fluoromethyl ketone (Z-VAD) and PD98059 were purchased from Beyotime Biotechnology. The AKT1-cDNA-pCMV expression vector was purchased from Sino Biological Inc. The AKT1 and ERK1 siRNAs were purchased from Shanghai GenePharma Co., Ltd. The Lipofectamine 2000 and Lipofectamine RNAiMAX transfection reagents were purchased from Life Technologies.

\section{Cytotoxicity assay}

The cell metabolism rate of the cell lines was measured using the MTT assay. Exponentially growing cells were treated for $24 \mathrm{~h}$ or $48 \mathrm{~h}$ with various concentrations (0$500 \mu \mathrm{mol} / \mathrm{L})$ of bicyclol in 96-well plates. DMSO-treated cells $(0.25 \%)$ were used as vehicle controls. MTT was then added to each well, and the cells were incubated for $4 \mathrm{~h}$ at $37^{\circ} \mathrm{C}$ in the dark. The Formazan crystals that formed were dissolved with $150 \mu \mathrm{l}$ of DMSO. The absorbance at $570 \mathrm{~nm}$ was measured using a Model ELX800 microplate reader (Bio-Tek Instruments). Each test was repeated at least three times. The cell metabolism rate was calculated by the following formula: \%cell metabolism rate $=($ mean absorbance in test wells $) /($ mean absorbance in control well) x $100 \%$.

\section{Cell death analysis}

Cell death, including apoptosis and necrosis, was assessed by staining with an annexin V-FITC/PI kit (Sigma), according to the manufacturer's instructions. Briefly, the cells were cultured with various concentrations of bicyclol for $48 \mathrm{~h}$, and then $1 \times 10^{6}$ cells were harvested and washed twice with ice-cold PBS. The apoptotic (Annexin V+/PI-) or necrotic cells (Annexin V $+/ \mathrm{PI}+)$ were evaluated by double staining with annexin
V-FITC and PI in binding buffer using flow cytometry (FAC sort, Becton Dickinson).

\section{Cell cycle analysis}

The cell cycle was analyzed by flow cytometry (FAC sort, Becton Dickinson). The cells were cultured with various concentrations of bicyclol for $24 \mathrm{~h}$, or with $200 \mu \mathrm{l}$ of bicyclol for 8,16 or $24 \mathrm{~h}$, and then suspended in $70 \%$ ethanol and fixed overnight at $4{ }^{\circ} \mathrm{C}$. The cells were then treated with $20 \mu \mathrm{g} / \mathrm{ml}$ RNase A, followed by $25 \mu \mathrm{g} / \mathrm{ml}$ propidium iodide (PI). The proportion of cells in G0/G1, $\mathrm{S}$ and $\mathrm{G} 2 / \mathrm{M}$ phases were determined by examining the intensity of PI fluorescence with a flow cytometer using an argon laser and $570 \mathrm{~nm}$ bandpass filters.

\section{Transient transfection and immunofluorescence}

The GFP-RFP-LC3 expression vector is widely used to detect autophagic flux [21]. The cells were transiently transfected with the GFP-RFP-LC3 expression vector (kindly provided by Prof. Mao Xiang [22]) using Lipofectamine 2000, according to the manufacturer's instructions. After the GFP-RFP-LC3-transfected cells were incubated for $48 \mathrm{~h}$, the cells were treated with bicyclol for an additional 24 $\mathrm{h}$. The GFP-RFP-LC3 fluorescence was observed using an Olympus FV1000 confocal microscope, and the autophagosomes (yellow dots) and autolysosomes (free red dots) in each cell were counted.

\section{Transient transfection of the activated AKT cDNA}

The HepG2 cells were transiently transfected with an AKT1-cDNA-pCMV expression vector using Lipofectamine 2000, according to the manufacturer's instructions as described above. After the AKT-cDNA-transfected cells were incubated for $48 \mathrm{~h}$, the cells were treated with bicyclol for an additional $24 \mathrm{~h}$. The subsequent assays were analyzed.

\section{Chemical inhibition}

The HepG2 cells were cultured and pre-treated with $20 \mu \mathrm{M}$ PD98059 for $30 \mathrm{~min}$, and then the cells were treated with various concentrations of bicyclol. Bicyclol and $10 \mu \mathrm{M}$ LY294002 were added to the cells at the same time. The subsequent assays were analyzed.

\section{siRNA knockdown of AKT and ERK1 expression}

The HepG2 cells were transiently transfected with AKT1 siRNA duplexes (sense, GGGCACUUUCGGCAA GGUGtt; antisense, CACCUUGCCGAAAGUGCCCtt) [23], ERK1 siRNA duplexes (sense, GAGCCGCCGC CGCCGCCATtt; antisense, ATGGCGGCGGCGGCGG CTCtt) [24], or non-specific control siRNA duplexes (GenePharma Co, Ltd) using the Lipofectamine RNAiMAX reagent, according to the manufacturer's instructions. After the siRNA-transfected cells were incubated 
for $48 \mathrm{~h}$, the cells were treated with bicyclol for an additional $24 \mathrm{~h}$. The subsequent assays were analyzed.

\section{Western blot analysis}

The treated cells were collected, washed in PBS and then lysed with lysis buffer on ice. Approximately $20 \mu \mathrm{g}$ of the lysed proteins were separated by sodium dodecyl sulfate-PAGE and transferred to a nitrocellulose blotting membrane. The membranes were blocked overnight in blocking buffer ( $5 \%$ bovine serum albumin solution and $0.05 \%$ Tween 20 in Tris-buffered saline (TBST)). After three washes in TBST, the membranes were probed with the indicated primary antibodies in blocking buffer for $1 \mathrm{~h}$. After three washes in TBST, the blots were incubated with the appropriate secondary antibodies for $1 \mathrm{~h}$ in blocking buffer. After three washes in TBST for $15 \mathrm{~min}$, the proteins were visualized by an Odyssey Imager (LI-COR).

\section{Transmission electron microscopy (TEM)}

After $24 \mathrm{~h}$ of bicyclol treatment, the cells were collected and then fixed in $2.5 \%$ glutaraldehyde in phosphate buffer (0.1 M, pH7.0) overnight. After three washes, the specimen was fixed with $1 \% \mathrm{OsO}_{4}$ in phosphate buffer (0.1 M, pH7.0) for $1 \mathrm{~h}$. After washing, the specimen was first dehydrated by a graded ethanol series $(30,50,70$, 80,90 and $100 \%$ ) for approximately $15 \mathrm{~min}$ at each step, and then incubated in pure acetone for $20 \mathrm{~min}$. Then, the specimen was placed in a 1:1 mixture of pure acetone and the final resin mixture for $1 \mathrm{~h}$, a 1:3 mixture of pure acetone and the final resin mixture for $3 \mathrm{~h}$, and the final spur resin mixture overnight. The specimen was then placed in spur resin and heated at $70{ }^{\circ} \mathrm{C}$ for more than $9 \mathrm{~h}$. Finally, the specimen was sectioned on a LEICA EM UC7 ultramicrotome, and sections were stained by uranyl acetate and alkaline lead citrate for $5 \mathrm{~min}$, respectively. The ultra-thin sections were viewed on a Hitachi Model H-7650 TEM.

\section{Statistical analysis}

The experimental results are expressed as the means \pm SD. The changes in the different assays were analyzed by the analysis of variance followed by Student's $t$ test. A value of $P<0.05$ was considered to be statistically significant.

\section{Results}

Bicyclol induced cell anti-proliferation, but not apoptosis

To examine whether bicyclol induces cytotoxic effects on different types of cancer cells, we treated HepG2, Hela, H292, A549 and LO2 cells with different concentrations of Bicyclol $(0,50,100,200$ and $500 \mu \mathrm{M})$ for $48 \mathrm{~h}$. DMSO-treated $(0.25 \%)$ cells were used as a vehicle control (Fig. 1b). After a $48 \mathrm{~h}$ exposure in $500 \mu \mathrm{M}$ bicyclol, the living cell number of HepG2 cells was significantly reduced to $39.1 \%$. Meanwhile, the inhibitory effect of bicyclol on Hela, LO2, A549 and H292 cells was less than the HepG2 cells. Bicyclol inhibited HepG2 cell proliferation in a time- and dose-dependent manner (Fig. 1c). These results indicated that bicyclol had different effects on hepatocellular carcinoma from normal liver cells and other tumor cells. The $\mathrm{IC}_{50}$ value for bicyclol in HepG2 cells is $0.30 \mathrm{mM}$ after a $48 \mathrm{~h}$ treatment (Fig. 1d).

We next investigated whether apoptosis could be the cause of the bicyclol-induced cell anti-proliferation; thus, an Annexin V-FITC/PI double staining assay was performed. The apoptotic (Annexin $\mathrm{V}^{+} / \mathrm{PI}^{-}$) or necrotic cells (Annexin $\mathrm{V}^{+} / \mathrm{PI}^{+}$) were identified by flow cytometry (Fig. 2). As shown in Fig. 2a, c, d, no significant increase in the number of necrotic cells was detected at any concentration of bicyclol used in this study, particularly compared with the positive control, $10 \mu \mathrm{M} \mathrm{H}_{2} \mathrm{O}_{2}$. Only $500 \mu \mathrm{M}$ bicyclol slightly increased the number of apoptotic cells, but the results were not statistically significant. Furthermore, we treated HepG2 cells with both bicyclol and the pan-caspase inhibitor Z-VAD, which blocks cell apoptosis. As shown in Fig. 2b, the cell proliferation after the co-treatment was similar to the treatment with bicyclol only. And the protein level of cleaved caspase-3 was investigated. As shown in Fig. 2e, no significant increase in the protein level of cleaved caspase-3, an apoptosis indicator, was detected at any concentration of bicyclol used, particularly compared with the positive control, $10 \mu \mathrm{M}$ Sorafenib, while Sorafenib effectively reduced cell viability (Additional file $1 \mathrm{~B}$ ) These results indicated that the bicyclol-induced cell antiproliferation was not dependent on apoptosis.

\section{Bicyclol induced cell cycle arrest and suppressed the growth regulatory signals in G1 phase}

A cell cycle analysis was performed to determine how bicyclol inhibited the growth of HepG2 cells (Fig. 3). The results showed a time- and dose-dependent increase in the percentage of cells in G1 phase and a decrease of the percentage of cells in $\mathrm{S}$ phase after bicyclol treatment (Fig. 3a, b). 53.34 \% of the PBS-treated cells were in G1 phase. After $24 \mathrm{~h}$ of treatment with 50, 100 and $200 \mu \mathrm{M}$ bicyclol, the percentage of cells in G1 phase increased to $58.54,60.67$ and $64.80 \%$, respectively (Fig. 3c).

The growth regulatory signals of G1 phase, including $\mathrm{Rb}$, cyclins, cyclin-dependent kinases and cyclindependent kinase inhibitors, can be further evidence of the G1/S cell cycle arrest. Phosphorylated Rb leads to the release of the E2F1 transcription factor and subsequent initiation of cell cycle progression to $S$ phase [25]. Therefore, we next investigated the cell cycle-related protein levels in cells treated with various concentration of bicyclol using western blot (Fig. 3d). As shown in 


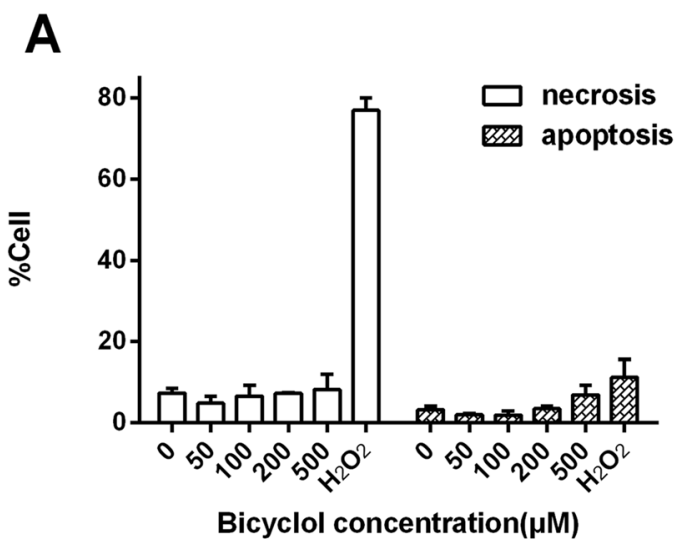

C

0

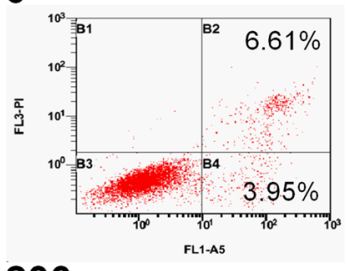

200

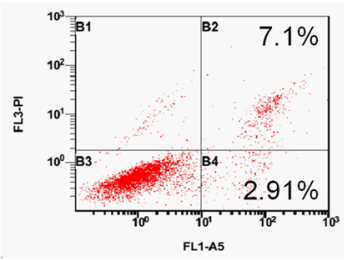

50

500
B

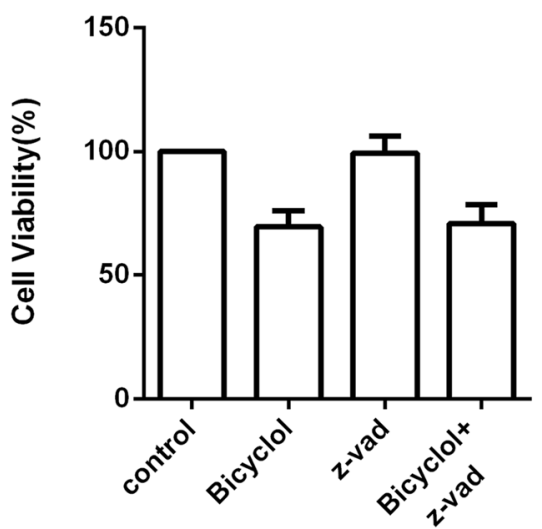

100

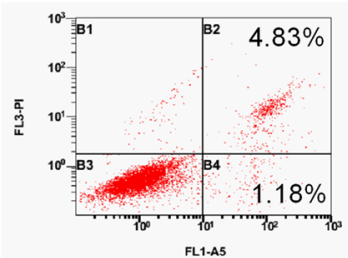

$\mathrm{H}_{2} \mathrm{O}_{2}$
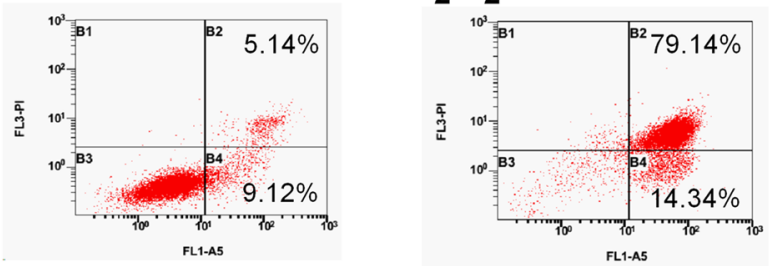

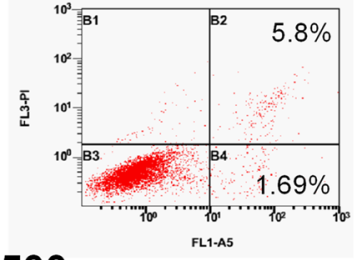

D

\begin{tabular}{lllllll}
\hline Bicyclol $(\mu \mathrm{M})$ & 0 & 50 & 100 & 200 & 500 & $\mathrm{H}_{2} \mathrm{O}_{2}$ \\
\hline Annexin V-/PI+ & $0.09 \pm 1.27$ & $0.59 \pm 0.45$ & $0.74 \pm 0.87$ & $0.71 \pm 1.08$ & $0.38 \pm 0.48$ & $5.27 \pm 4.94$ \\
Annexin V+/PI+ & $7.37 \pm 1.07$ & $4.82 \pm 1.76$ & $6.65 \pm 2.57$ & $7.25 \pm 0.33$ & $8.20 \pm 3.83$ & $76.94 \pm 3.11$ \\
Annexin V-/PI- & $89.21 \pm 0.04$ & $82.59 \pm 1.13$ & $90.67 \pm 4.54$ & $88.52 \pm 1.78$ & $84.51 \pm 4.70$ & $6.59 \pm 2.59$ \\
Annexin V+/PI- & $3.26 \pm 0.98$ & $2.01 \pm 0.31$ & $1.95 \pm 1.09$ & $3.52 \pm 0.54$ & $6.9 \pm 2.39$ & $11.21 \pm 4.43$ \\
\hline
\end{tabular}

E

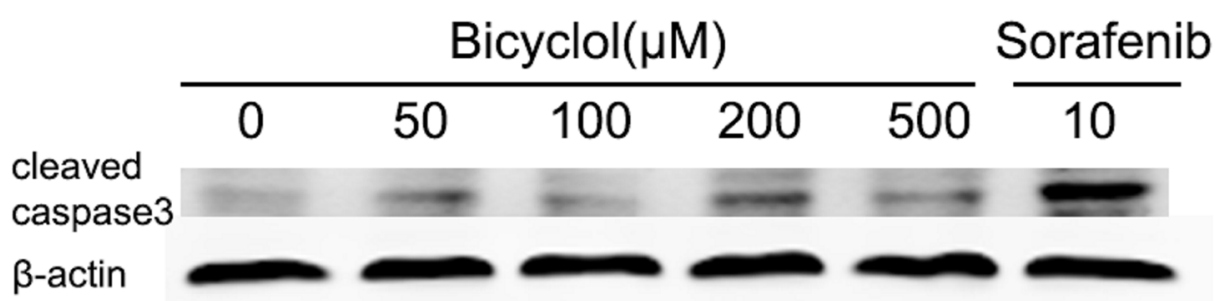


(See figure on previous page.)

Fig. 2 Bicyclol did not induce apoptosis or necrosis in HepG2 cells. a The percent of apoptotic and the necrotic cells after $24 \mathrm{~h}$ of treatment with different concentrations of bicyclol were measured by flow cytometry. $\mathrm{H}_{2} \mathrm{O}_{2}$-treated $(10 \mu \mathrm{M})$ cells were used as positive controls. $\mathbf{b}$ Living cell number after co- treatment with bicyclol and z-vad. HepG2 cells were treated with $20 \mu \mathrm{M} z$-vad and $500 \mu \mathrm{M}$ bicyclol at the same time. The cells treated with either $20 \mu \mathrm{M} z$-vad or $200 \mu \mathrm{M}$ bicyclol were used as controls. After a $24 \mathrm{~h}$ exposure, the cells were incubated with MTT and the $A_{570}$ was measured. c Flow cytometry analysis of cancer cell apoptosis using the Annexin V-FITC/PI dual-labeling technique. The B2 gate (Annexin $\mathrm{V}^{+} / \mathrm{PI}^{+}$) represents the percentage of necrotic cells, while the B4 gate (Annexin $\mathrm{V}^{+} / \mathrm{PI}^{-}$) represents the percentage of apoptotic cells. Up to 10,000 cells were counted in each sample. $\mathbf{d}$ The percent of cells identified by flow cytometry. e The protein level of cleaved caspase-3 treated by bicyclol and Sorafenib

Fig. 3d, the level of phosphorylated Rb was dramatically decreased after bicyclol treatment. In addition, the expression of the cyclin D1, cyclin D3 and cyclin E2 proteins were decreased after treatment with $500 \mu \mathrm{M}$ bicyclol. Meanwhile, the expression of the CDK2 and CDK4 proteins were decreased, while the cyclin-dependent kinase inhibitors $\mathrm{p} 21^{\mathrm{CIP}}$ and $\mathrm{p} 27^{\mathrm{KIP} 1}$ were increased in a dosedependent manner. The increase in the expression of the $\mathrm{p} 21^{\mathrm{CIP}}$ and $\mathrm{p} 27^{\mathrm{KIP} 1}$ proteins and the decrease in cyclins and cyclin-dependent kinases dephosphorylate $\mathrm{Rb}$ and lead to cell cycle arrest, which may contribute to the antiproliferative effects of bicyclol in HepG2 cells.

\section{Bicyclol induced autophagy in HepG2 cells}

Autophagy is a physiological cellular strategy and survival mechanism under stress conditions. Moreover, overactivated autophagy may result in cell anti-proliferation [26]. LC3 is a hallmark of autophagy, and the conversion of cytosolic LC3-I to autophagosome membranebound LC3-II is a specific marker for autophagosome formation [27]. Thus, a GFP-RFP-LC3 plasmid was transfected into HepG2 cells and investigated by fluorescence microscopy. As shown in Fig. 4a, b, the amount of free red dots (indicating autolysosomes) and the amount of yellow dots (indicating autophagosomes) were significantly increased after treatment with $200 \mu \mathrm{M}$ bicyclol. Furthermore, co-treatment with bicyclol and 3-methyladenine (3-MA, a chemical inhibitor of autophagy) reduced the autophagy-inducing and anti-proliferation effects of bicyclol (Fig. 4d). The cellular ultrastructure was analyzed by transmission electron microscopy, which markedly demonstrated the presence of bicyclol-induced autolysosomes (Fig. 4c). A western blot assay was performed to detect the conversion of LC3-I to LC3-II. As shown in Fig. 4e, the conversion was up-regulated by bicyclol in a dose-dependent manner. The results suggested that bicyclol induced autophagy in HepG2 cells.

\section{Bicyclol inhibited the PI3K/Akt/mTOR and the Ras/Raf/ MEK/ERK pathways}

As mentioned above, bicyclol induced cell cycle arrest and autophagy in HepG2 cells. However, the pathways downstream of these bicyclol-mediated effects were investigated in-depth. As shown in Fig. 5a, Akt phosphorylation at Ser473 and Thr450 was remarkably inhibited, while the total protein level of Akt remained constant, which suggested that the PI3K/AKT pathway was involved in bicyclol-mediated cell anti-proliferation in HepG2 cells. Dephosphorylated AKT directly inhibits TSC1/2 and activates PRAS40 to inactivate mTORC1 and induce autophagy [28, 29]. Furthermore, mTOR phosphorylation at Ser2448 was inhibited after bicyclol treatment, which indicated that bicyclol induced autophagy in HepG2 cells through the PI3K/AKT/ mTOR pathway.

We next investigated whether the Ras/Raf/MEK/ERK pathway was involved in the bicyclol-induced cell antiproliferation as well. The Ras protein level was significantly reduced after bicyclol exposure. Additionally, ERK1/2 phosphorylation at Thr202 and Tyr 204 was inhibited, while the total protein level was constant. These results suggested that the synergy between the PI3K/AKT pathway and the Ras/Raf/MEK/ERK pathway played an important role in the bicyclol-induced antiproliferative effect.

\section{Transfection of the constitutively active AKT CDNA suppressed the bicyclol-induced anti-proliferative effects in HepG2 cells}

Our results showed that bicyclol targets the AKT signaling pathway. To confirm the role of the AKT signaling pathway in bicyclol-induced cell cycle arrest and autophagy, we next transfected HepG2 cells with a constitutively active form of the AKT cDNA and treated the AKToverexpressing cells with bicyclol (Fig. 5b, c d, e). The expression level of total AKT was significantly increased, which confirmed the success of transfection. Transfected cells expressing the active AKT cDNA were considerably more resistant to bicyclol than cells transfected with the control cDNA. The living cell number was increased from 72.3 to $89.1 \%$ (Fig. 5b). The bicyclolinduced cell cycle arrest was rescued after transfection, while the percentage of cells in G1 phase was decreased from 78.5 to 76.3 \% (Fig. 5c, and DNA distribution was presented in Additional file 2A). Moreover, 
A

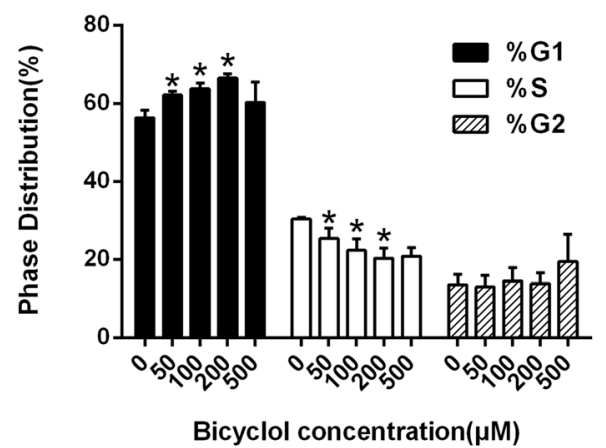

B

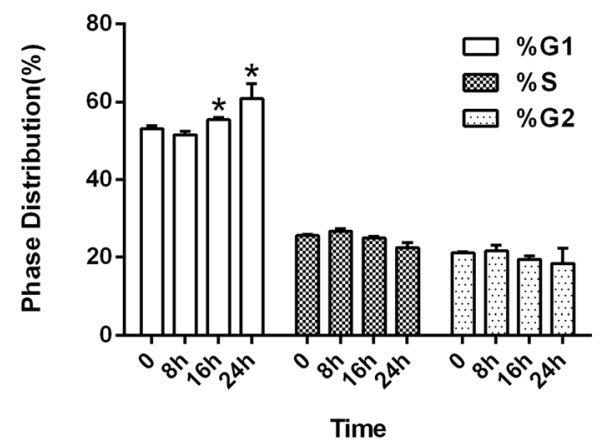

C

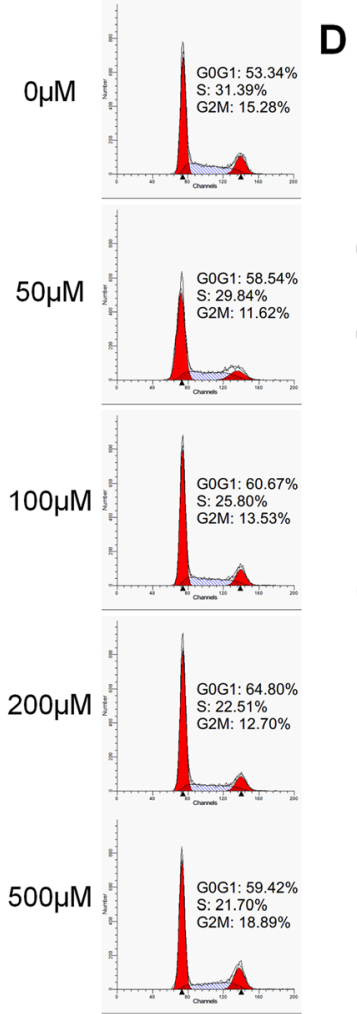

D

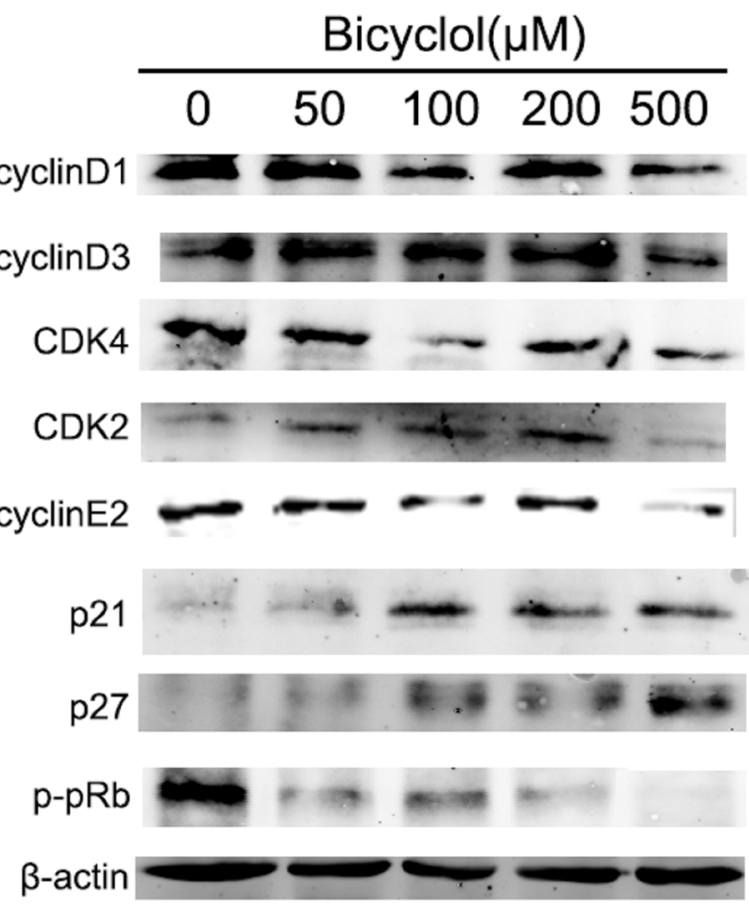

Fig. 3 Bicyclol induced G1 cycle arrest in HepG2 cells on a dose- and time-dependent manner. a The phase distribution of HepG2 cells treated with various concentrations $(0,50,100,200$ and $500 \mu \mathrm{M})$ of bicyclol for $24 \mathrm{~h}$ was analyzed by flow cytometry. The HepG2 cells were plated in six-well plates and cultured until they reached $60 \%$ confluence. The cells were incubated in serum-free RPMl 1640 culture medium for $24 \mathrm{~h}$ to be synchronized. Then the cells were treated with bicyclol for $24 \mathrm{~h}$. The cell cycle distribution was determined by flow cytometry with the propidium iodide (PI) dye, and distribution of cells in G1, S, and G2 phases was calculated using the Cell Quest software. $\mathbf{b}$ The phase distribution of HepG2 cells treated with $200 \mu \mathrm{M}$ bicyclol for 8, 16 and $24 \mathrm{~h}$ was analyzed by flow cytometry. The cells were treated as in (A). c The DNA distribution of cells treated with various concentrations of bicyclol for $24 \mathrm{~h}$. $\mathbf{d}$ Dose-dependent effects of bicyclol on cell cycle-related proteins in HepG2 cells. The cells were disrupted after treatment with various concentrations $(0,50,100,200$ and $500 \mu \mathrm{M})$ of bicyclol for $12 \mathrm{~h}$. The proteins were collected, and cellular $\beta$-actin, cyclin D1, cyclin D3, cyclin E2, CDK2, CDK4, p21, p27 and p-Rb (Ser 807) were analyzed by western blotting. $\left({ }^{*} p<0.05\right.$ versus PBS control)

the fluorescence microscopy results showed that the amount of autolysosomes and autophagosomes were significantly decreased after transfection (Fig. 5e). Furthermore, the LC3-I to LC3-II conversion was restored in AKT-overexpressing cells compared to the control. In addition, AKT phosphorylation at Ser473 and
ERK1/2 phosphorylation at Thr202 and Tyr 204 were rescued after transfection, which led to $\mathrm{Rb}$ phosphorylation and resulted in a decrease in the percent of cells in G1 phase (Fig. 5d). These results further confirmed that the AKT signaling pathway is indeed the target of bicyclol treatment. 

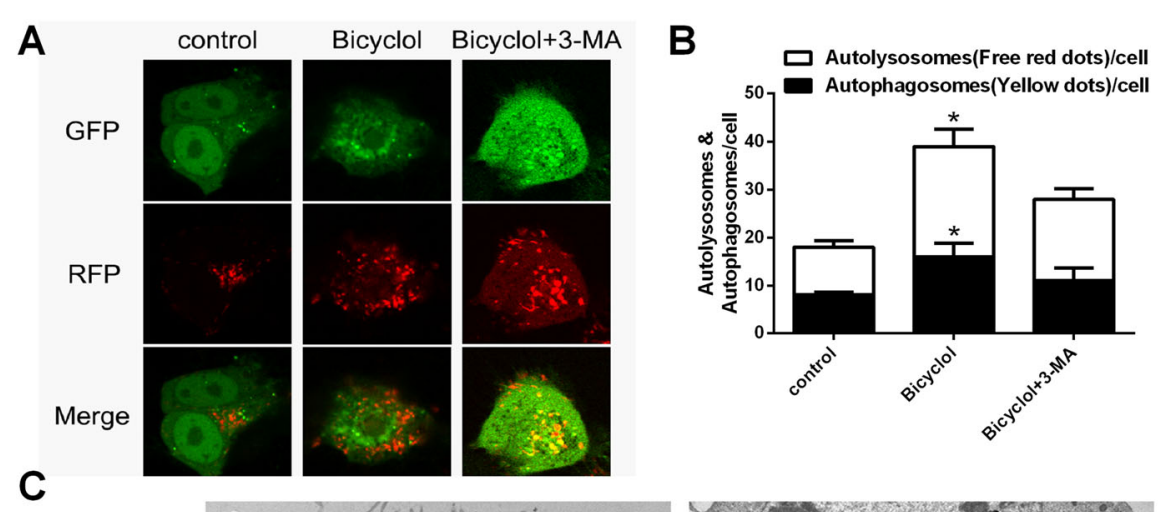

C
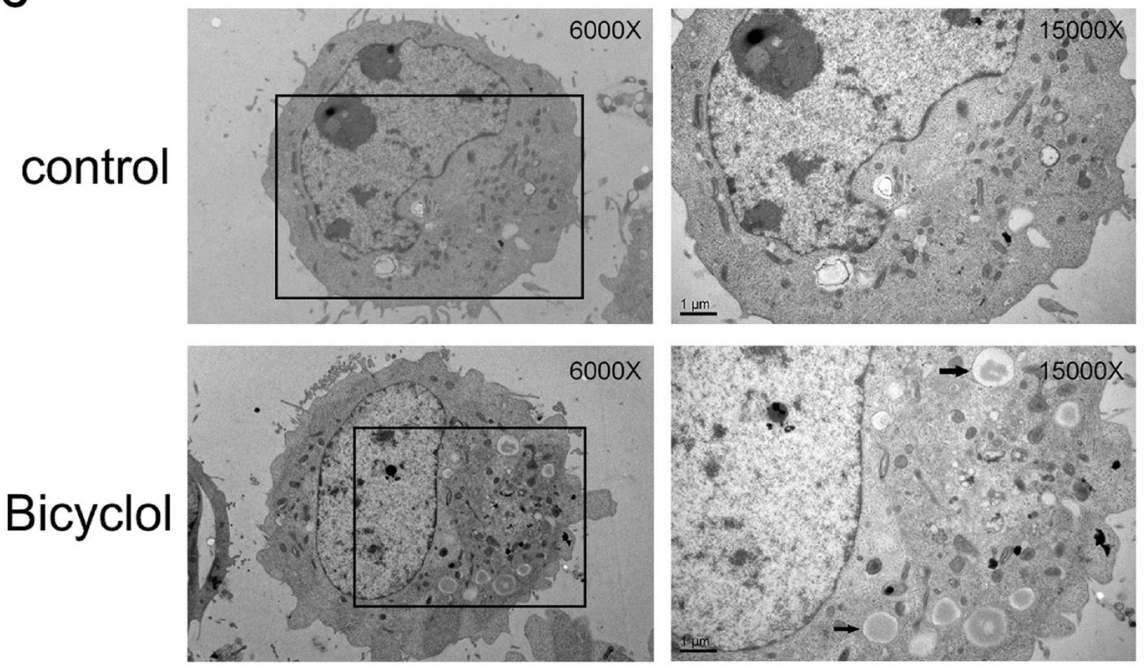

D

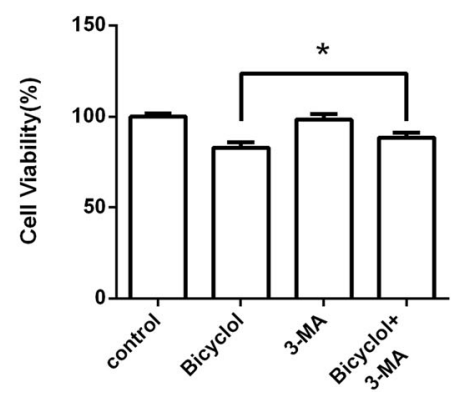

E

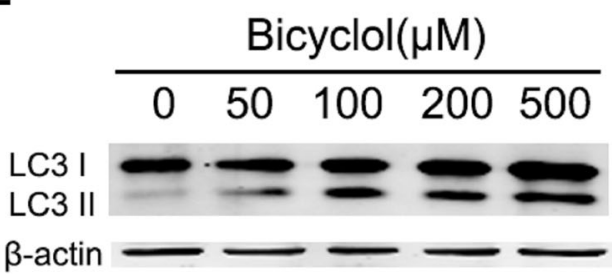

Fig. 4 Bicyclol induced autophagy in HepG2 cells. a Autophagy flux was induced by bicyclol and inhibited by 3-MA. The cells were transiently transfected with GFP-RFP-LC3 vectors using Lipofectamine 2000 and incubated for $48 \mathrm{~h}$, and then treated with $200 \mu \mathrm{M}$ bicyclol for another $24 \mathrm{~h}$ or pre-treated with 5 mM 3-MA for 30 min. The GFP-RFP-LC3 fluorescence was observed by a confocal microscope, and the number of autophagosomes (yellow dots) and autolysosomes (free red dots) in each cell were counted by ImageJ. 50 cells for each condition were counted. b The number of autophagosomes and autolysosomes were increased by bicyclol, and 3-MA suppressed the effect. c The cellular ultrastructure was analyzed by transmission electron microscopy. The cells were incubated in 6-well plates and treated with $200 \mu \mathrm{M}$ bicyclol for $24 \mathrm{~h}$. Then, the cells were collected and fixed. Next, ultra-thin sections were viewed on a TEM. The autolysosomes were indicated by arrows. $\mathbf{d}$ Cell proliferation after co-treatment with bicyclol and 3-MA. The cells were incubated in 96-well plates and then pre-treated with 5 mM 3-MA for 30 min. Next, the 3-MA was removed and the cells were treated with $200 \mu \mathrm{M}$ bicyclol for $24 \mathrm{~h}$. The $\mathrm{A}_{570}$ was then measured after the MTT incubation. e The levels of the LC3 I and II proteins were influenced by bicyclol. The cells were treated with various concentrations of bicyclol for $12 \mathrm{~h}$ and then disrupted. The proteins were collected, and cellular LC3 I and II were analyzed by western blotting. $\beta$-actin was used as the loading control. Bar graphs represent the means \pm SD from three independent experiments. ( ${ }^{*} p<0.05$ versus bicyclol treatment)

\section{LY294002 and PD98059 enhanced the anti-proliferative effect of bicyclol}

To further confirm the central role of the AKT signaling pathway and the Ras/Raf/MEK/ERK signaling pathway in bicyclol-induced cell cycle arrest and autophagy, we co-treated HepG2 cells with bicyclol and LY294002, a PI3K inhibitor, or PD98059, a MEK inhibitor (Fig. 6). The MTT assay results showed that cell proliferation 


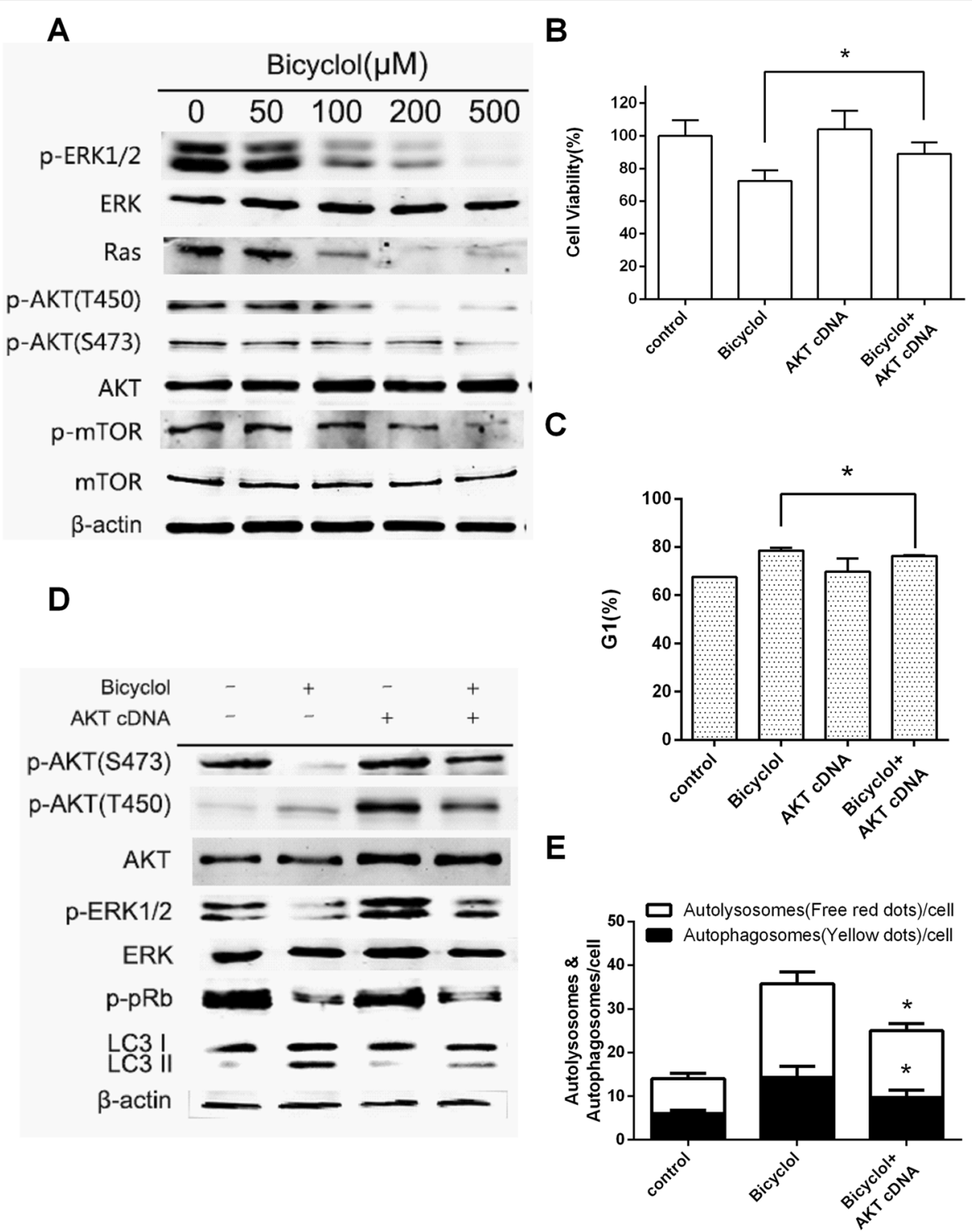

Fig. 5 Bicyclol suppressed the PI3K/AKT and the Ras/Raf/MEK/ERK pathways. a Dose-dependent effects of bicyclol on the PI3K/AKT and the Ras/ Raf/MEK/ERK pathway-related proteins. The cells were disrupted after treatment with various concentrations (0, 50, 100, 200 and $500 \mu \mathrm{M})$ of bicyclol for 6 h. The proteins were collected, and cellular $\beta$-actin, p-ERK1/2 (Thr202 and Tyr 204), total ERK, Ras, p-AKT (Thr 450), p-AKT (Ser 473), total AKT, p-mTOR (Ser 2448), and total mTOR were analyzed by western blotting. b The AKT cDNA rescued HepG2 cells from bicyclol-induced cell anti-proliferation. The cells were transiently transfected with the AKT CDNA expression vector using Lipofectamine 2000 and incubated for $48 \mathrm{~h}$. Then, the transfected cells were treated with $200 \mu \mathrm{M}$ bicyclol for $48 \mathrm{~h}$. The $\mathrm{A}_{570}$ was measured after the MTT incubation. c The bicyclol-induced G1 arrest was reduced by the AKT cDNA. The cells were transfected with the AKT cDNA expression vector and then treated with $200 \mu \mathrm{M}$ bicyclol for $24 \mathrm{~h}$. The phase distribution was determined by flow cytometry. $\mathbf{d}$ The AKT cDNA suppressed the effect of bicyclol on the PI3K/AKT and the Ras/Raf/MEK/ERK pathways. The cells were transfected with the AKT cDNA expression vector and then treated with $200 \mu \mathrm{M}$ bicyclol for $6 \mathrm{~h}$. The cells were disrupted, and cellular $\beta$-actin, p-AKT (Thr 450), p-AKT (Ser 473), total AKT, p-ERK1/2 (Thr202 and Tyr 204), total ERK, p-Rb (Ser 807) and LC3 I and II were analyzed by western blotting. e The number of autophagosomes and autolysosomes were reduced by the AKT cDNA. Bar graphs represent the means \pm SD from three independent experiments. $\left({ }^{*} p<0.05\right.$ versus bicyclol treatment)

was significantly decreased after $24 \mathrm{~h}$ and $48 \mathrm{~h}$ of cotreatment with bicyclol and LY294002 compared to treatment with only bicyclol as a control (Fig. 6a). Moreover, cell proliferation was significantly decreased after $48 \mathrm{~h}$ of co-treatment with bicyclol and PD98059. Furthermore, the percentage of cells in G1 phase was remarkably increased from 68.7 to $71.8 \%$ after co-treatment with bicyclol and LY294002 (Fig. 6b, and DNA Distribution was 


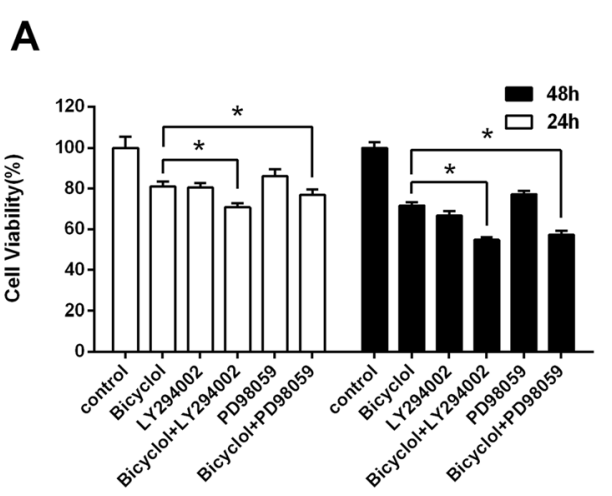

B

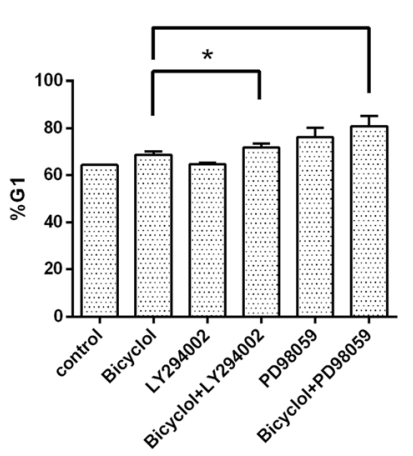

C

D
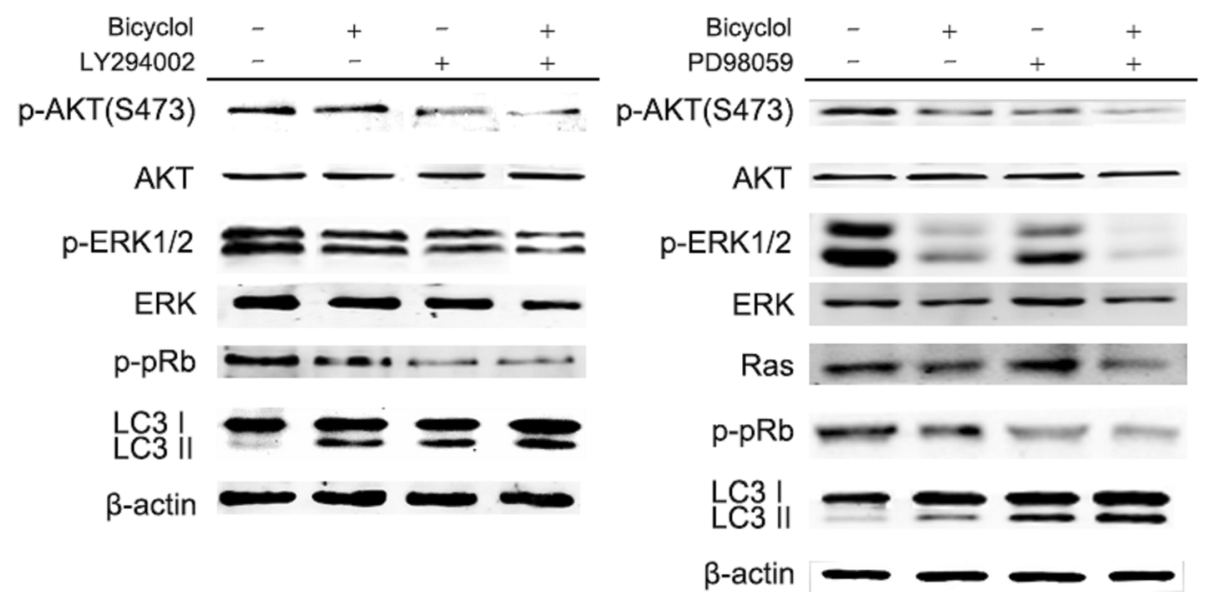

E

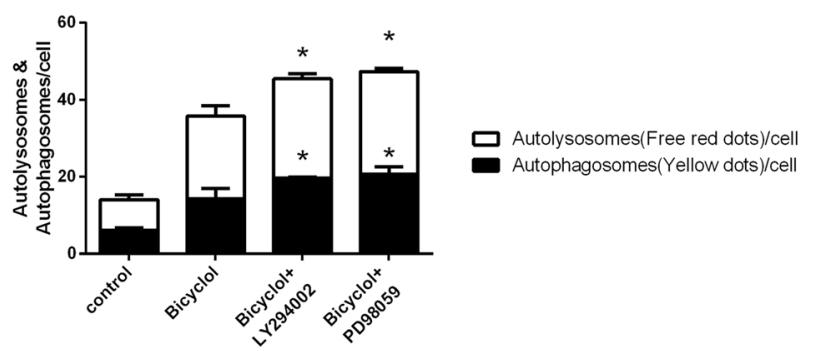

Fig. 6 LY294002 and PD98059 enhanced the anti-proliferative effect of bicyclol in HepG2 cells. a Cell proliferation after co-treatment with LY294002 and bicyclol or PD98059 and bicyclol. The cells were treated with both $10 \mu \mathrm{M} \mathrm{LY} 294002$ and $200 \mu \mathrm{M}$ bicyclol for 24 or 48 h, or cells were pre-treated with $20 \mu \mathrm{M}$ PD98059 for $30 \mathrm{~min}$ and then $200 \mu \mathrm{M}$ bicyclol was added to the media for 24 or $48 \mathrm{~h}$. The $\mathrm{A}_{570}$ was then measured after the MTT incubation. b The percentage of cells in G1 phase after co-treatment with LY294002 and bicyclol or PD98059 and bicyclol. The cells were treated as in (A) for $24 \mathrm{~h}$, and the percent of cells in G1 phase was determined by flow cytometry. c The bicyclol-mediated protein levels after co-treatment with LY294002 and bicyclol. Cells were pre-treated with both $10 \mu \mathrm{M}$ LY294002 and $200 \mu \mathrm{M}$ bicyclol for $6 \mathrm{~h}$. Then, the cells were disrupted, and cellular $\beta$-actin, p-AKT (Ser 473), total AKT, p-ERK1/2 (Thr202 and Tyr 204), total ERK, p-Rb (Ser 807) and LC3 I and II were analyzed by western blotting. $\mathbf{d}$ The bicyclol-mediated protein levels after co-treatment with PD98059 and bicyclol. The cells were pre-treated with $20 \mu \mathrm{M}$ PD98059 for $30 \mathrm{~min}$ and then $200 \mu \mathrm{M}$ bicyclol was added to the media for $6 \mathrm{~h}$. Then, the cells were disrupted, and cellular $\beta$-actin, p-AKT (Ser 473), total AKT, p-ERK1/2 (Thr202 and Tyr 204), total ERK, Ras, p-Rb (Ser 807) and LC3 I and II were analyzed by western blotting. e The autophagosomes and autolysosomes were increased by LY294002 and PD98059. The cells were transiently transfected with GFP-RFP-LC3 vectors using Lipofectamine 2000 and incubated for $48 \mathrm{~h}$. Then the cells were treated with both $10 \mu \mathrm{M}$ LY294002 and $200 \mu \mathrm{M}$ bicyclol for $24 \mathrm{~h}$, or cells were pre-treated with $20 \mu \mathrm{M}$ PD98059 for $30 \mathrm{~min}$ and then $200 \mu \mathrm{M}$ bicyclol was added to the media for $24 \mathrm{~h}$. The GFP-RFP-LC3 fluorescence was observed by a confocal microscope, and the number of autophagosomes (yellow dots) and autolysosomes (free red dots) in each cell were counted by ImageJ. 50 cells for each condition were counted. Bar graphs represent the means \pm SD from three independent experiments. $\left({ }^{*} p<0.05\right.$ versus bicyclol treatment) 
presented in Additional file 2B). Additionally, the percentage of cells in G1 phase was increased from 68.7 to $80.9 \%$ after co-treatment with bicyclol and PD98059. The amount of autolysosomes and autophagosomes were also significantly increased after co-treatment with bicyclol and LY294002 compared to treatment with only bicyclol (Fig. 6e). In addition, the LC3-I to LC3-II conversion in AKT-inhibited cells was enhanced. Furthermore, AKT phosphorylation at Ser473 and ERK1/2 phosphorylation at Thr202 and Tyr 204 were inhibited after the co-treatment, which led to $\mathrm{Rb}$ dephosphorylation and resulted in an increase in the percent of cells in G1 phase (Fig. 6c). However, the amount of autolysosomes and autophagosomes were significantly increased after treatment with bicyclol and PD98059. The LC3-I to LC3-II conversion in ERKinhibited cells was enhanced as well (Fig. 6e). In addition, AKT phosphorylation at Ser473 and ERK1/2 phosphorylation at Thr202 and Tyr 204 were inhibited after the co-treatment, which led to Rb dephosphorylation and resulted in an increase in the percent of cells in G1 phase (Fig. 6d, and DNA Distribution was presented in Additional file 2C). Moreover, the expression level of Ras was constant. Taken together, these findings suggested that bicyclol induced cell cycle arrest and autophagy through the PI3K/AKT and the Ras/Raf/MEK/ERK pathways.

\section{Genetic silencing of AKT and ERK enhanced bicyclol- mediated cell cycle arrest and autophagy}

Although LY294002 and PD98059 are relatively selective inhibitors of AKT and MEK, they may influence other proteins that mediate cell cycle or autophagy. Therefore, we also used small interfering RNAs (siRNAs) to specifically silence AKT and ERK and evaluate the effect of AKT and ERK silencing on bicyclol-mediated cell cycle arrest and autophagy. Thus, HepG2 cells were transfected with a pool of siRNAs targeting AKT or ERK before bicyclol treatment. The transfection efficiency was verified by western blot assay (Fig. 7d). As shown in Fig. $7 \mathrm{a}$, the combination of genetic silencing of AKT and treatment with $200 \mu \mathrm{M}$ bicyclol for $48 \mathrm{~h}$ reduced the living cell number to $9.4 \%$, while treatment with bicyclol alone reduced the living cell number to $73.4 \%$. Additionally, the combination of genetic silencing of ERK and treatment with $200 \mu \mathrm{M}$ bicyclol for $48 \mathrm{~h}$ reduced the living cell number to $10.6 \%$, while treatment with bicyclol only reduced the living cell number to $73.4 \%$ (Fig. 7b). The flow cytometry results showed that specific knockdown of AKT and ERK expression enhanced the bicyclol-induced G1 arrest (Fig. 7c, , and DNA Distribution was presented in Additional file 1A). Furthermore, a GFP-RFP-LC3 and siRNA co-transfection was established and investigated by fluorescence microscopy. As shown in Fig. 7e, genetic silencing of AKT and ERK significantly enhanced the bicyclol-induced increase in the amount of autolysosomes and autophagosomes compared with bicyclol treatment alone. These influences of siRNA-mediated AKT and ERK silencing on bicyclolinduced cell cycle arrest and autophagy agree with the results from the chemical inhibitors, indicating that bicyclol suppresses the PI3K/AKT and the Ras/Raf/MEK/ ERK pathways, leading to LC3 conversion, inhibition of the growth regulatory signals of G1 phase, and eventually cell cycle arrest at G1 phase and autophagy.

\section{Discussion}

At present, bicyclol is a novel synthetic drug that has been widely used in the clinic to treat patients with chronic hepatitis B viral infections [6]. The previous studies focused on its protective effects against hepatotoxin-induced liver injury, but the anti-cancer potential of bicyclol remained unexplored. From previous studies [13], bicyclol has protective effects and induces expression of heat shock protein 27 under $100 \mathrm{uM}$ at less than $24 \mathrm{~h}$. In this study, we found that bicyclol induces cell cycle arrest at G1 phase and autophagy at more than $100 \mathrm{uM}$, and we also identified the molecular mechanism, showing that bicyclol suppresses both the PI3K/ AKT pathway and the Ras/Raf/MEK/ERK pathway and downregulates cyclin D, cyclin E and mTOR, leading to $\mathrm{Rb}$ dephosphorylation and the conversion of LC3I to LC3II.

We found that bicyclol treatment of HepG2 cells caused a dose-dependent increase in the percentage of cells in G1 phase. Therefore, we specifically focused on proteins that regulate the cell cycle. CDK2 and CDK4 play a central role in cell cycle progression by forming complexes with cyclin E and D1, respectively [30, 31]. By binding to cyclin Ds, CDK4 phosphorylates the Rb protein to release $\mathrm{Rb}$ from the E2F complex, leading to transactivation of the E2F target genes important for $\mathrm{S}$ phase [32-34]. By binding to cyclin Es, CDK2 also can phosphorylate the $\mathrm{Rb}$ protein and control the transition into $S$ phase [35]. As shown in Fig. 3, bicyclol not only inhibited CDK2-cyclin E and CDK4-cyclin D expression but also suppressed $\mathrm{Rb}$ phosphorylation in a dosedependent manner. Intrinsic CDK inhibitors, such as $\mathrm{p} 21^{\mathrm{CIP} 1}$ and $\mathrm{p} 27^{\mathrm{KIP} 1}$, which appear to be the primary negative regulators during proliferation in a variety of cell types, induce G1 cell cycle arrest by binding to the CDK-cyclin complex and inhibiting its kinase activity [36-38]. Our results suggested that $\mathrm{p}{ }^{\mathrm{CIP} 1}$ and $\mathrm{p} 27^{\mathrm{KIP} 1}$ upregulation, inhibition of levels of the CDK2-cyclin $\mathrm{E}$ and CDK4-cyclin D complexes, and Rb down-regulation contribute to the anti-proliferative effects of bicyclol in HepG2 cells.

We investigated the pathways that regulate cell cycle arrest at G1/S checkpoint to further confirm which 


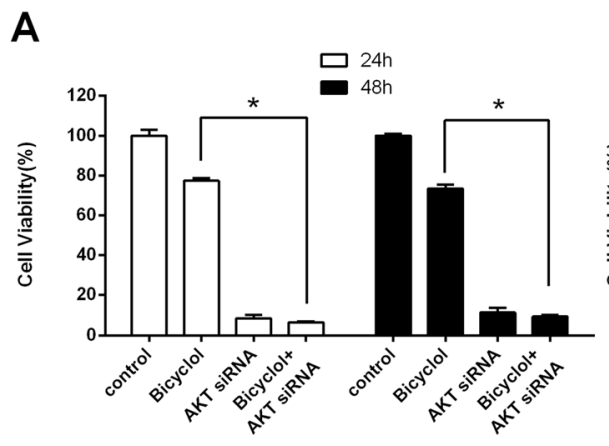

C

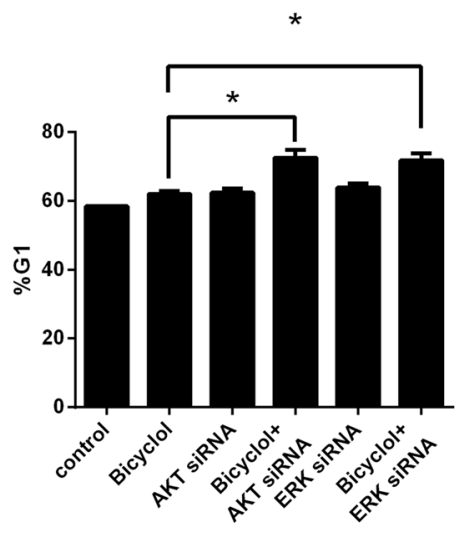

E

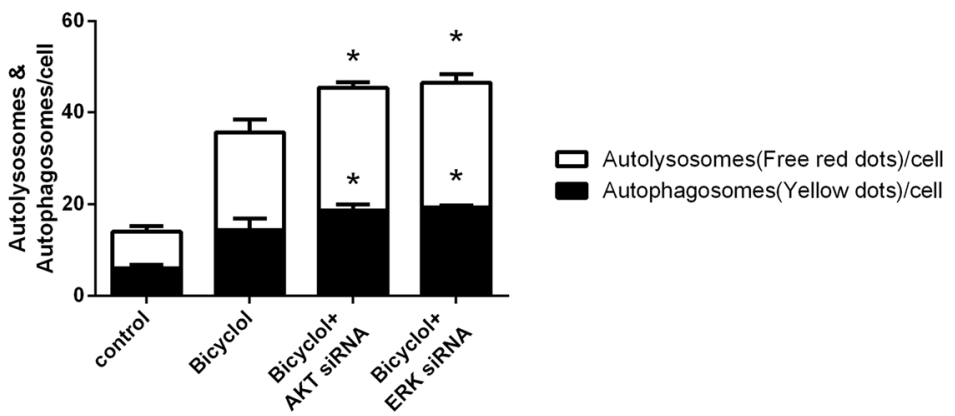

B

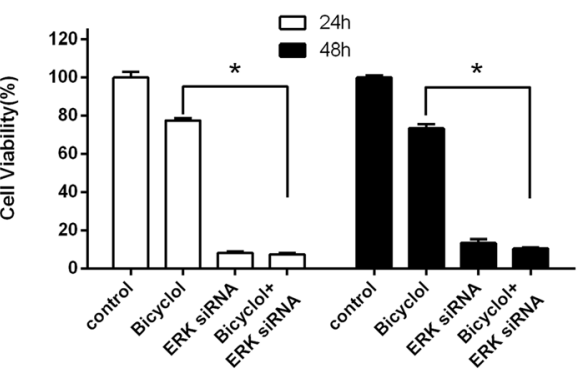

D

\section{control ERK siRNA}

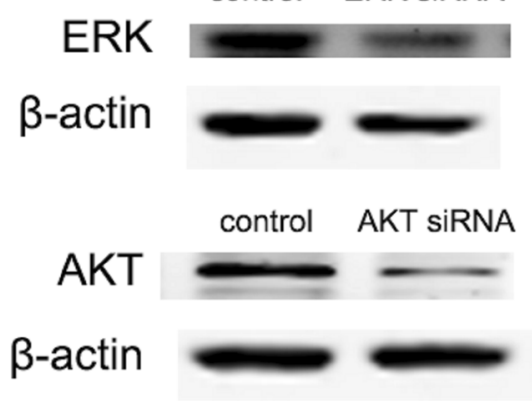

Fig. 7 AKT and ERK siRNAs enhanced the anti-proliferative effect of bicyclol in HepG2 cells. a Cell proliferation after AKT inhibition and bicyclol treatment. The cells were transiently transfected with the AKT siRNA using Lipofectamine RNAiMAX and incubated for $48 \mathrm{~h}$. Then, the transfected cells were treated with $200 \mu \mathrm{M}$ bicyclol for 24 or $48 \mathrm{~h}$. The $A_{570}$ was then measured after the MTT incubation. $\mathbf{b}$ Living cell number after ERK inhibition and bicyclol treatment. The cells were transiently transfected with the ERK siRNA using Lipofectamine RNAiMAX and incubated for $48 \mathrm{~h}$. Then, the transfected cells were treated with $500 \mu \mathrm{M}$ bicyclol for 24 or $48 \mathrm{~h}$. The $\mathrm{A}_{570}$ was then measured after the MTT incubation. c The percent of cells in G1 phase after AKT or ERK inhibition and bicyclol treatment. The cells were treated as in (A) with $200 \mu \mathrm{M}$ bicyclol for $24 \mathrm{~h}$, and the percentage of cells in G1 phase was determined by flow cytometry. $\mathbf{d}$ The transfection efficiency of the AKT and ERK siRNAs. The cells were transiently transfected with AKT or ERK siRNAs using Lipofectamine RNAiMAX and incubated for $48 \mathrm{~h}$. Then, the cells were disrupted, and cellular $\beta$-actin, total AKT and total ERK were analyzed by western blotting. e The number of autophagosomes and autolysosomes was increased by AKT or ERK inhibition. The cells were co-transfected with the GFP-RFP-LC3 vector and AKT/ERK siRNAs using Lipofectamine 2000, incubated for 48 h, and then treated with $200 \mu \mathrm{M}$ bicyclol for another $24 \mathrm{~h}$. The GFP-RFP-LC3 fluorescence was observed by a confocal microscope, and the number of autophagosomes (yellow dots) and autolysosomes (free red dots) in each cell was counted. Bar graphs represent the means \pm SD from three independent experiments. ( ${ }^{*} p<0.05$ versus bicyclol treatment)

pathways were downstream of bicyclol. In this study, bicyclol dephosphorylates Akt at Ser 473 and downregulates the PI3K/AKT pathway in HepG2 cells. The PI3K/
AKT pathway plays a major role in many carcinogenic processes, such as cell growth and differentiation, and AKT phosphorylation at Ser473 is essential for maximal 
Akt activation [39]. Compelling evidence suggests that expression of phosphor-Ser473 Akt in primary human breast cancers was statistically correlated with $\mathrm{p} 27^{\mathrm{KIP} 1}$ expression in the tumor cytosol [40]. Moreover, activated Akt directly phosphorylates and inhibits $\mathrm{p}^{\mathrm{CIP} 1}$ [41], indirectly activates cyclin $\mathrm{D}$, and, thus, induces cell cycle progression [42]. In this study, we speculated that the bicyclol-induced Akt inactivation subsequently upregulated the level of $\mathrm{p} 21^{\mathrm{CIP} 1}$ and $\mathrm{p} 27^{\mathrm{KIP} 1}$ transcription, thereby blocking cell cycle progression at G1 phase by suppressing CDK2 and CDK4 activity. The Ras/Raf/ MEK/ERK pathway is also inhibited by bicyclol. Blocking ERK activity blocks cyclin D1 expression and cell proliferation [43]. Additionally, activated ERK is essential for the assembly of the cyclin E/CDK2 complex [44]. Thus, ERK plays an important role in the G1/S checkpoint. In this study, we suggested that the bicyclol-induced ERK inactivation downregulated the cyclin D/CDK4 and cyclin E/CDK2 complexes. Furthermore, the PI3K/AKT and the Ras/Raf/MEK/ERK pathways can interact in multiple ways. MEK can activate Akt activity in hematopoietic cells [45], and Akt can contribute to Raf1 inactivation in some cells. However, it is not clear how bicyclol mediates the two pathways, which needs further studies.

The PI3K/AKT and the Ras/Raf/MEK/ERK pathways also play an important role in autophagy. Activated Akt directly phosphorylates the protein encoded by the TSC2 tumor suppressor gene [46]. The phosphorylation blocks TSC2 binding with TSC1, and subsequently prevents formation of the TSC1/2 complex [47]. Akt can also inhibit PRAS40, which then activates mTORC1 and induces autophagy [29]. ERK also phosphorylates and inhibits TSC1/TSC2, which then activates mTORC1 and induces autophagy [48]. The mTOR complex 1 (mTORC1) consists of mTOR, RAPTOR, PRAS40, mLST8, DEPTOR, and the Tti1/Tel2 complex [49-52]. mTORC1 can phosphorylate the autophagy-related gene 13 (ATG13) [53] and the autophagy/beclin 1 regulator 1 (AMBRA1) [54], which inhibits the autophagy-initiating UNC-5-like autophagy activating kinase (ULK) complex. On the other hand, the mTORC1 can also regulate the VPS34 complex by phosphorylating ATG14 L [55]. Therefore, mTORC1 inhibition induces ULK1/2 complex and the VPS34 complex activity, leading to the conversion of LC3I to LC3II, a specific marker of autophagosome formation, and eventually induces autophagy. Our findings demonstrated that bicyclol inhibited p-mTOR, converted LC3I to LC3II, and induced autophagosome formation and autophagy. The amount of autolysosomes and autophagosomes were significantly increased after co-treatment with bicyclol and LY294002 (or PD98059). In addition, AKT or ERK knockdown by siRNA enhanced bicyclol-induced autophagy. Based on the above analysis, we conclude that the bicyclol-induced autophagy is closely associated with the PI3K/AKT and the Ras/Raf/MEK/ERK pathways.

\section{Conclusions}

In conclusion, bicyclol inhibited cell cycle progression at G1 phase and induced autophagy in HepG2 cells, and the drug didn't increase cell apoptosis or necrosis. The anti-proliferative effect of bicyclol was considered as the result of combination of cell cycle arrest and autophagy, leading to induced cell proliferation in MTT results. Our mechanistic study indicated that the cytotoxicity of bicyclol is closely associated with the inhibition of the PI3K/AKT pathway and the Ras/Raf/MEK/ERK pathway. The results contribute to our understanding of bicyclol and provide clear evidence for its promising potential in preclinical and clinical situations.

\section{Additional files}

\begin{abstract}
Additional file 1: (A) The DNA distribution of cells treated with bicyclolsiRNA-, bicyclol + siRNA-,bicyclol-AKT siRNA+, bicyclol + AKT siRNA+, bicyclol-ERK siRNA+ and bicyclol + ERK siRNA+. The siRNA was transfected as mentioned in Methods. Then the cells were treated with bicyclol for $24 \mathrm{~h}$. (B) MTT results of HepG2 cell viability with treatment $500 \mu \mathrm{M}$ Bicyclol or $10 \mu \mathrm{M}$ Sorafenib. (TIF $696 \mathrm{~kb}$ )

Additional file 2: (A) The DNA distribution of cells treated with bicyclolAKT CDNA-, bicyclol-AKT CDNA+, bicyclol + AKT cDNA- and bicyclol + AKT CDNA+. The cDNA was transfected as mentioned in Methods. Then the cells were treated with bicyclol for $24 \mathrm{~h}$ (B) The DNA distribution of cells treated with bicyclol or/and LY294002 for 24 h. (C) The DNA distribution of cells treated with bicyclol or/and PD98059 for 24 h. (TIF 809 kb)
\end{abstract}

\section{Abbreviations}

3-MA: 3-methyladenine; AKT: v-akt murine thymoma viral oncogene homolog; CDK: Cyclin-dependent kinases; ERK: Extracellular signal-regulated kinases; FITC: Fluorescein isothiocyanate; GFP: Green fluorescent protein; LC3: Light chain 3; Mdm2: Mouse double minute 2 homolog; MEK: Mitogen/ extracellular signal-regulated kinase; mTOR: Mammalian target of rapamycin; mTORC1: mTOR complex 1; NF-kB: Nuclear factor kappa-light-chain-enhancer of activated B cells; PAGE: Polyacrylamide gel electrophoresis; PBS: Phosphate buffer saline; PI: Propidium iodide; PI3K: Phosphatidylinositide 3-kinases; Rb: Retinoblastoma protein; RFP: Red fluorescent protein; siRNA: Small interfering RNA; TSC: Tuberous sclerosis complex

\section{Acknowledgements}

We thank the highly qualified native English-speaking editors (Elsevier's WebShop) for editing work. This work was supported by grant 81302680 from the National Natural Science Foundation of China and 2013 M541791 from the Postdoctoral Science Foundation Project of China.

\section{Funding}

This work was supported by grant 81302680 from the National Natural Science Foundation of China and 2013 M541791 from the Postdoctoral Science Foundation Project of China.

\section{Availability of data and materials}

Data sharing not applicable to this article as no datasets were generated or analysed during the current study.

\section{Authors' contributions}

YW drafted the project design, planned and conducted experiments, analyzed the data and wrote the text. HN contributed to project design and discussed the data and text. XZ conducted experiments and analyzed data. YQ and XG 
contributed to project design, text writing and discussion of the data and text All authors read and approved the final manuscript.

\section{Competing interests}

The authors declare that they have no competing interests.

\section{Consent for publication}

The manuscript didn't include any details, images, or videos relating to individual participants.

\section{Ethics approval and consent to participate}

Research didn't involve any human subjects, human material, or human data.

Received: 31 December 2015 Accepted: 6 September 2016

Published online: 21 September 2016

\section{References}

1. Jemal A, Bray F, Center MM, Ferlay J, Ward E, Forman D. Global cancer statistics. CA Cancer J Clin. 2011;61(2):69-90.

2. Ferlay J, Shin H, Bray F, Forman D, Mathers C, Parkin D. GLOBOCAN 2008, cancer incidence and mortality worldwide: IARC CancerBase No. 10. Lyon, France: International Agency for Research on Cancer. 2010;2010:29.

3. Parkin DM, Bray F, Ferlay J, Pisani P. Global cancer statistics, 2002. CA Cancer J Clin. 2005:55(2):74-108.

4. Parkin DM, Pisani P, Ferlay J. Global cancer statistics. CA Cancer J Clin. 1999; 49(1):33-64. 1.

5. Wang $\mathrm{H}$, Li Y. Protective effect of bicyclol on acute hepatic failure induced by lipopolysaccharide and d-galactosamine in mice. Eur J Pharmacol. 2006; 534(1-3):194-201.

6. Zhao D, Liu G. Protective effect of bicyclol on concanavalin A-induced liver nuclear DNA injury in mice. Zhonghua yi xue za zhi. 2001;81(14):844-8.

7. Li Y, Dai G-W, Li Y, Liu G-t. Effect of bicyclol on acetaminophen-induced hepatotoxicity: energetic metabolism and mitochondrial injury in acetaminophen-intoxicated mice. Yaoxue Xuebao. 2001;36(10):723-6.

8. Liu GT, Li Y, Wei HL, Zhang H, Xu JY, Yu LH. Mechanism of protective action of bicyclol against CCl4-induced liver injury in mice. Liver Int. 2005; 25(4):872-9.

9. Zhao J, Chen H, Li Y. Protective effect of bicyclol on acute alcohol-induced liver injury in mice. Eur J Pharmacol. 2008;586(1-3):322-31.

10. Yao G-b, Xu D-Z, Lan P, Xu C-b, Wang C, Luo J, et al. Efficacy and safety of bicyclol in treatment of 2,200 chronic viral hepatitis. Zhongguo Xinyao yu Linchuang Zazhi. 2005;24(6):421-6.

11. Bao XQ, Liu GT. Bicyclol: a novel antihepatitis drug with hepatic heat shock protein 27/70-inducing activity and cytoprotective effects in mice. Cell Stress Chaperones. 2008;13(3):347-55.

12. Bao XQ, Liu GT. Induction of overexpression of the 27-and 70-kDa heat shock proteins by bicyclol attenuates concanavalin A-induced liver injury through suppression of nuclear factor-kappa B in mice. Mol Pharmacol. 2009;75(5):1180-8.

13. Bao XQ, Liu GT. Bicyclol protects HepG2 cells against D-galactosamine-induced apoptosis through inducing heat shock protein 27 and mitochondria associated pathway. Acta Pharmacol Sin. 2010;31(2):219-26.

14. Falasca M. PI3K/Akt signalling pathway specific inhibitors: a novel strategy to sensitize cancer cells to anti-cancer drugs. Curr Pharm Design. 2010; 16(12):1410-6.

15. Hennessy BT, Smith DL, Ram PT, Lu YL, Mills GB. Exploiting the PI3KNAKT pathway for cancer drug discovery. Nat Rev Drug Discov. 2005:4(12):988-1004.

16. Vara JÁF, Casado E, de Castro J, Cejas P, Belda-Iniesta C, González-Barón M. PI3K/Akt signalling pathway and cancer. Cancer Treat Rev. 2004;30(2):193-204.

17. Shelton JG, Steelman LS, White ER, McCubrey JA. Synergy between PI3K/Akt and Raf/MEK/ERK pathways in IGF-1R mediated cell cycle progression and prevention of apoptosis in hematopoietic cells. Cell Cycle. 2004;3(3):372-9.

18. Roovers K, Assoian RK. Integrating the MAP kinase signal into the G1 phase cell cycle machinery. Bioessays. 2000;22(9):818-26.

19. Pruitt K, Der CJ. Ras and Rho regulation of the cell cycle and oncogenesis. Cancer Lett. 2001:171(1):1-10.

20. Gysin S, Lee SH, Dean NM, McMahon M. Pharmacologic inhibition of RAF - > MEK - > ERK signaling elicits pancreatic cancer cell cycle arrest through induced expression of p27(Kip1). Cancer Res. 2005;65(11):4870-80.
21. Park M, Sabetski A, Chan YK, Turdi S, Sweeney G. Palmitate induces ER stress and autophagy in $\mathrm{H} 9 \mathrm{c} 2$ cells: implications for apoptosis and adiponectin resistance. J Cell Physiol. 2015;230(3):630-9.

22. Sun MX, Huang L, Wang R, Yu YL, Li C, Li PP, et al. Porcine reproductive and respiratory syndrome virus induces autophagy to promote virus replication. Autophagy. 2012:8(10):1434-47.

23. Kuo PL, Hsu YL, Cho CY. Plumbagin induces G(2)-M arrest and autophagy by inhibiting the AKT/mammalian target of rapamycin pathway in breast cancer cells. Mol Cancer Ther. 2006:5(12):3209-21.

24. Glennon PE, Kaddoura S, Sale EM, Sale GJ, Fuller SJ, Sugden PH. Depletion of mitogen-activated protein kinase using an antisense oligodeoxynucleotide approach downregulates the phenylephrine-induced hypertrophic response in rat cardiac myocytes. CircRes. 1996;78(6):954-61.

25. Tamrakar S, Rubin E, Ludlow JW. Role of pRB dephosphorylation in cell cycle regulation. Front Biosci. 2000;5:D121-D37.

26. Su ZY, Yang ZZ, Xu YQ, Chen YB, Yu Q. Apoptosis, autophagy, necroptosis, and cancer metastasis. Mol Cancer. 2015;14:14

27. Choi $\mathrm{CH}$, Jung $\mathrm{YK}$, Oh SH. Selective induction of catalase-mediated autophagy by dihydrocapsaicin in lung cell lines. Free Radic Biol Med. 2010;49(2):245-57.

28. Saucedo LJ, Gao XS, Chiarelli DA, Li L, Pan D, Edgar BA. Rheb promotes cell growth as a component of the insulin/TOR signalling network. Nat Cell Biol. 2003;5(6):566-71.

29. Vander Haar E, Lee S, Bandhakavi S, Griffin TJ, Kim DH. Insulin signalling to mTOR mediated by the Akt/PKB substrate PRAS40. Nat Cell Biol. 2007;9(3):316-U126.

30. Lim SH, Kaldis P. Cdks, cyclins and CKls: roles beyond cell cycle regulation. Development. 2013;140(15):3079-93.

31. Chen WJ, Chang CY, Lin JK. Induction of G1 phase arrest in MCF human breast cancer cells by pentagalloylglucose through the down-regulation of CDK4 and CDK2 activities and up-regulation of the CDK inhibitors p27(Kip) and p21(Cip). Biochem Pharmacol. 2003:65(11):1777-85.

32. Sherr CJ. D-type cyclins. Trends BiochemSci. 1995;20(5):187-90.

33. Kato J, Matsushime H, Hiebert SW, Ewen ME, Sherr CJ. Direct binding of cyclin $\mathrm{D}$ to the retinoblastoma gene product (pRb) and pRb phosphorylation by the cyclin D-dependent kinase CDK4. Genes Dev. 1993;7(3):331-42.

34. Santamarina M, Hernandez G, Zalvide J. CDK redundancy guarantees cell cycle progression in Rb-negative tumor cells independently of their p16 status. Cell Cycle. 2008;7(13):1962-72.

35. Sever-Chroneos Z, Angus SP, Fribourg AF, Wan HJ, Todorov I, Knudsen KE, et al. Retinoblastoma tumor suppressor protein signals through inhibition of cyclin-dependent kinase 2 activity to disrupt PCNA function in S phase. Mol Cell Biol. 2001:21(12):4032-45.

36. Polyak K, Kato JY, Solomon MJ, Sherr CJ, Massague J, Roberts JM, et al. P27(KIP1), a cyclin-Cdk inhibitor, links transforming growth-factor-beta and contact inhibition to cell-cycle arrest. Genes Dev. 1994;8(1):9-22.

37. Polyak $K$, Lee $M H$, Erdjumentbromage $H$, Koff A, Roberts JM, Tempst $P$, et al. Cloning of p27(kip1), a cyclin-dependent kinase inhibitor and a potential mediator of extracellular antimitogenic signals. Cell. 1994;78(1):59-66.

38. Eldeiry WS, Tokino T, Velculescu VE, Levy DB, Parsons R, Trent JM, et al. WAF1, a potential mediator of p53 tumor suppression. Cell. 1993:75(4):817-25.

39. Alessi DR, Andjelkovic M, Caudwell B, Cron P, Morrice N, Cohen P, et al. Mechanism of activation of protein kinase B by insulin and IGF-1. Embo J. 1996;15(23):6541-51

40. Shin I, Yakes FM, Rojo F, Shin NY, Bakin AV, Baselga J, et al. PKB/Akt mediates cell-cycle progression by phosphorylation of p27(Kip1) at threonine 157 and modulation of its cellular localization. Nat Med. 2002:8(10):1145-52.

41. Zhou BHP, Liao Y, Xia WY, Spohn B, Lee NH, Hung MC. Cytoplasmic localization of p21(Cip1/WAF1) by Akt-induced phosphorylation in HER2/neu-overexpressing cells. Nat Cell Biol. 2001;3(3):245-52.

42. Diehl JA, Cheng MG, Roussel MF, Sherr CJ. Glycogen synthase kinase 3 beta regulates cyclin D1 proteolysis and subcellular localization. Genes Dev. 1998; 12(22):3499-511.

43. Lavoie JN, Lallemain G, Brunet A, Muller R, Pouyssegur J. Cyclin D1 expression is regulated positively by the p42/p44(MAPK) and negatively by the p38/ HOG(MAPK) pathway. J Biol Chem. 1996:271(34):20608-16.

44. Lents NH, Keenan SM, Bellone C, Baldassare JJ. Stimulation of the Raf/MEK ERK cascade is necessary and sufficient for activation and Thr-160 phosphorylation of a nuclear-targeted CDK2. J Biol Chem. 2002;277(49): 47469-75.

45. Shelton JG, Moye PW, Steelman LS, Blalock WL, Lee JT, Franklin RA, et al. Differential effects of kinase cascade inhibitors on neoplastic and cytokinemediated cell proliferation. Leukemia. 2003;17(9):1765-82. 
46. He CC, Klionsky DJ. Regulation mechanisms and signaling pathways of autophagy. Annu Rev Genet. 2009;43:67-93.

47. Inoki K, Li Y, Zhu TQ, Wu J, Guan KL. TSC2 is phosphorylated and inhibited by Akt and suppresses mTOR signalling. Nat Cell Biol. 2002;4(9):648-57.

48. Ma L, Chen ZB, Erdjument-Bromage H, Tempst P, Pandolfi PP. Phosphorylation and functional inactivation of TSC2 by Erk: Implications for tuberous sclerosis and cancer pathogenesis. Cell. 2005;121(2):179-93.

49. Peterson TR, Laplante M, Thoreen CC, Sancak Y, Kang SA, Kuehl WM, et al. DEPTOR is an mTOR inhibitor frequently overexpressed in multiple myeloma cells and required for their survival. Cell. 2009;137(5):873-86.

50. Kaizuka T, Hara T, Oshiro N, Kikkawa U, Yonezawa K, Takehana K, et al. Tti and Tel2 Are critical factors in mammalian target of rapamycin complex assembly. J Biol Chem. 2010;285(26):20109-16.

51. Hara K, Maruki Y, Long XM, Yoshino K, Oshiro N, Hidayat S, et al. Raptor, a binding partner of target of rapamycin (TOR), mediates TOR action. Cell. 2002;110(2):177-89.

52. Sancak Y, Thoreen CC, Peterson TR, Lindquist RA, Kang SA, Spooner E, et al. PRAS40 is an insulin-regulated inhibitor of the mTORC1 protein kinase. Mol Cell. 2007;25(6):903-15.

53. Jung $\mathrm{CH}$, Jun $\mathrm{CB}$, Ro S-H, Kim Y-M, Otto NM, Cao J, et al. ULK-Atg13-FIP200 complexes mediate mTOR signaling to the autophagy machinery. Mol Biol Cell. 2009;20(7):1992-2003.

54. Nazio F, Strappazzon F, Antonioli M, Bielli P, Cianfanelli V, Bordi M, et al. mTOR inhibits autophagy by controlling ULK1 ubiquitylation, self-association and function through AMBRA1 and TRAF6. Nat Cell Biol. 2013;15(4):406.

55. Yuan H-X, Russell RC, Guan K-L. Regulation of PIK3C3NNPS34 complexes by MTOR in nutrient stress-induced autophagy. Autophagy. 2013;9(12):1983-95.

\section{Submit your next manuscript to BioMed Central and we will help you at every step:}

- We accept pre-submission inquiries

- Our selector tool helps you to find the most relevant journal

- We provide round the clock customer support

- Convenient online submission

- Thorough peer review

- Inclusion in PubMed and all major indexing services

- Maximum visibility for your research

Submit your manuscript at www.biomedcentral.com/submit 